\title{
Competência em Informação e Desinfodemia no contexto da pandemia de Covid-19
}

\author{
Information Literacy and Disinfodemic in the Covid-19 Pandemic
}

\begin{abstract}
Marianna Zattar ${ }^{\mathrm{a}, ~ *}$ (1)
RESUMO: A educação no âmbito informacional pode ser um caminho para o controle da infodemia e da desinfodemia neste contexto pandêmico. Deste modo, apresenta-se aqui o resultado de uma pesquisa cujo objetivo central é indicar duas ações de competência em informação, no âmbito da desinfodemia da COVID-19. Para tanto, uma pesquisa qualitativa é realizada a partir de um recorte teórico-conceitual assentado em quatro conceitos analíticos entre infodemia, desinformação, desinfodemia e competência em informação, do ponto de vista da educação nas dinâmicas informacionais. A competência em informação é apresentada no escopo das ações voltadas para o público-alvo das informações falsas sobre a COVID-19, com o objetivo de promover o pensamento crítico e a avaliação de fontes de informação, em diferentes ambientes e dinâmicas informacionais. Como resultado, e com o objetivo de ilustrar duas dinâmicas em competência em informação, são apresentadas as iniciativas da International Federation of Library Associations and Institutions (IFLA) e do VI Fórum sobre Competência em Informação: pesquisas e práticas, realizado no Rio de Janeiro, na perspectiva da educação em informação. Conclui que iniciativas de competência em informação devem ser vistas sob a perspectiva da promoção dos direitos dos cidadãos na medida em que a educação em dinâmicas informacionais pode promover práticas informacionais críticas, éticas e solidárias.
\end{abstract}

Palavras-chave: Competência em Informação; Desinformação; Infodemia; Desinfodemia.

ABSTRACT: Informational education can be a way to control infodemic and disinfodemic in this pandemic context. In this way, the result of a research whose central objective is to present two actions of information literacy, within the scope of the disinfodemic of COVID-19, is disclosed here. For this, a qualitative research is carried out from a theoretical-conceptual perspective based on four analytical concepts between infodemic, disinformation, disinfodemic and information literacy, from the point of view of education in informational dynamics. Information literacy is presented within the scope of actions aimed at the target audience of false information about COVID-19, with the objective of promoting critical thinking and the assessment of information sources, in different environments and information dynamics. The result, with the objective of illustrating two dynamics in information literacy, is seen in the initiatives of the International Federation of Library Associations and Institutions (IFLA) and the VI Forum de Competência em Informação: pesquisas e práticas, carried out in Rio de Janeiro, from the perspective of information education. It concludes that initiatives of information literacy seen from the perspective of promoting citizens' rights as education in information dynamics can promote critical, ethical and solidary information practices.

Keywords: Information Literacy; Disinformation; Infodemic; Disinfodemic.

\footnotetext{
a Curso de Biblioteconomia e Gestão de Unidades de Informação, Faculdade de Administração e Ciências Contábeis, Centro de Ciência Jurídicas e Econômicas, Universidade Federal do Rio de Janeiro, Rio de Janeiro, RJ, Brasil.

*Correspondência para/Correspondence to: Marianna Zattar. E-mail: mzattar@facc.ufrj.br.

Recebido em/Received: 10/09/2020; Aprovado em/Approved: 29/11/2020.

Artigo publicado em acesso aberto sob licença CC BY 4.0 Internacional
} 


\section{INTRODUÇÃO}

Em janeiro de 2020, a Organização Mundial da Saúde (OMS) declarou que o surto da doença causada pelo novo coronavírus (COVID-19) constituía uma Emergência de Saúde Pública, de abrangência internacional, de acordo com o Regulamento Sanitário Internacional. Em março do mesmo ano, foi caracterizada como uma pandemia ${ }^{1}$ (ORGANIZAÇÃO PAN-AMERICANA DA SAÚDE, 2020).

A COVID-19 é uma doença infecciosa causada pelo coronavírus, denominado SARS-CoV2, que pode se apresentar sob diferentes formas e modos, que vão de infecções assintomáticas ao óbito. A pandemia evidencia, entre outras coisas, as desigualdades sociais (SANTOS, 2020), que podem ser decisivas na vida. Os casos de infecções graves não são a maioria, mas sobrecarregam as estruturas médicas e hospitalares das mais diversas regiões do mundo e podem exigir que equipes de saúde tenham que decidir sobre a morte de pacientes por falta de condição básica de atendimento hospitalar adequado.

Alguns países tomaram medidas preventivas, a partir de informações baseadas em evidências médicas e clínicas e conseguiram evitar a propagação dos casos. No entanto, alguns governos ignoraram as informações científicas. No Brasil a infecção foi chamada de "gripezinha" pelo presidente, o que tem levado a assistir o aumento do número de casos e de mortes ${ }^{2}$, sendo certo que, na maioria das vezes, tal atitude é motivada por disputas políticas e apelos econômicos.

O crescimento de uma doença infecciosa, em escala global, tem como um dos efeitos o aumento no volume de informações sobre o tema, visto que todas as pessoas são potencialmente interessadas no assunto. Ocorre que a estratégia de desconsiderar e deslegitimar o conhecimento científico, em meio à uma infodemia (termo usado pela OMS para se referir ao volume de informação), possibilita que as informações falsas (desinformação) também surjam em maior proporção, o que configura a desinfodemia, tal como foi denominada pela Organização das Nações Unidas para a Educação, a Ciência e a Cultura (Unesco).

Alguns fatores promovem a desinfodemia: (1) a pós-verdade, na medida em que as pessoas acreditam em algo, sem que os fatos tenham acontecido, porque têm sentimentos que fortalecem a sua crença e opinião; sobre opinião, tem-se ainda (2) a polarização, em que o ódio assume um protagonismo onde a intencionalidade de causar prejuízo ao outro torna-se uma missão; (3) a relação entre produção e consumo informacional também pode fortalecer a desinfodemia, visto que não há mais uma segmentação de quem faz e de quem usa a informação; (4) as tecnologias de informação e comunicação, que possibilita (5) disseminação e compartilhamento de informação, em um clique, em mídias sociais digitais que podem atingir milhares e milhões de pessoas. (WARDLE; DERAKHSHAN, 2017; POSETTI; BONTCHEVA, 2020; UNESCO, 2020).

Neste contexto, a educação em informação surge como uma alternativa para evitar a infodemia, ao mesmo tempo que pode ser tratamento para combater a desinfodemia. Desse modo, torna-se o objetivo central é apresentar duas ações de competência em informação, no âmbito da desinfodemia da COVID-19. Para tanto, uma pesquisa

\footnotetext{
${ }^{1}$ O surto e pandemia se diferenciam pelo alcance e número de casos de uma doença nas regiões. De modo simplificado, tem-se que o surto é local e a pandemia tem escala global.

2 "O número de casos confirmados de COVID-19 no Brasil tem sido amplamente subnotificado. Neste trabalho, estimamos que o número real de casos foi cerca de 11 vezes maior do que os atualmente informados." (PRADO et al., 2020).
} 
qualitativa é realizada a partir de um recorte teórico-conceitual assentado em quatro conceitos analíticos entre infodemia, desinformação, desinfodemia e competência em informação, do ponto de vista da educação nas dinâmicas informacionais.

\section{INFODEMIA}

A noção de infodemia, em definição com base na Organização Mundial da Saúde (OMS), em 2020, é a propagação de informações em volume excessivo, que, por suas características essencialmente quantitativas, podem ter como reflexo também a disseminação de informações falsas (ou imprecisas) que atrapalham o acesso às fontes confiáveis em meio à hiperinformação disponível sobre um tema.

No contexto de um mundo pandêmico, em que as janelas (físicas e digitais) nos trazem o mundo, mais do que as portas, em meio ao distanciamento social necessário, enquanto as vacinas e cura ainda estão em processo de pesquisa, temos também problemas relacionados à COVID-19, aqueles das dinâmicas informacionais, na medida em que as informações falsas ou imprecisas emergem quase que na mesma velocidade da propagação do vírus. Tais informações, que podem ser sobre o surgimento, os sintomas, a transmissão, a cura e as intervenções institucionais, contaminam a sociedade nos diferentes ambientes informacionais, ao interferirem diretamente na saúde física, mental e emocional dos indivíduos.

Como termo, de acordo com Evanildo Bechara, da Academia Brasileira de Letras, a infodemia pode ser observada a partir da junção do radical "info", de informação, do grego dêmos, de povo, e o sufixo "ia", formador de substantivos da terminologia médica (BECHARA, 2020).

Desse modo, tem-se que infodemia seria algo como "informação do/ para o povo no âmbito da saúde" e se refere ao volume de informações associadas a um assunto médico específico, que podem se multiplicar exponencialmente em pouco tempo, devido a um evento específico, como a pandemia atual do novo corona vírus, e causar, entre outras coisas, crises na saúde pública. A infodemia, portanto, não está relacionada à qualidade ou ao tipo de informação e sim à quantidade de modo primário, ou seja, o excesso de informação atrapalha na verificação da confiabilidade e/ ou da veracidade. Tem-se que a quantidade sem qualquer tipo de organização engloba rumores, boatos e muitos outros tipos de desinformações, impactando significativamente o dia-a-dia da sociedade em escala global ou mundial, a partir da manipulação de informações com intenção duvidosa que prejudica a saúde pública, seja em nível clínico, médico ou social.

As referências sobre o assunto remetem ao ano de 2020. Por meio da busca básica realizada por assunto no Portal de Periódicos da Coordenação de Aperfeiçoamento de Pessoal do Ensino Superior/ Ministério da Educação (Portal CAPES/MEC) foram identificadas 28 publicações sobre o tema, todas publicadas neste ano. Todavia, em busca realizada em bases de dados referenciais, como a Scopus, por exemplo, pode-se identificar um artigo científico que data do primeiro semestre de 2019, e que tem como autores um grupo de pesquisadores de Casablanca, no Marrocos ${ }^{3}$. 0 artigo foi publicado no periódico Mathematics e fala, entre outras coisas, sobre a influência da

\footnotetext{
3 EL KIHAL, Fadwa et al. Role of media and effects of infodemics and escapes in the spatial spread of epidemics: A stochastic multi-region model with optimal control approach. Mathematics, v. 7, n. 3, 2019.
} 
desinformação nas dificuldades de vacinação e a necessidade de evitar visões equivocadas no controle de epidemias.

Destaca-se também entre as primeiras publicações sobre infodemia, o artigo "How to fight an infodemic" ", que apresenta a ação da OMS para combater a desinformação sobre a COVID-19, publicado em fevereiro de 2020, no periódico The Lancet, identificado nas bases de dados Web of Science, Biblioteca Virtual em Saúde (BVS), PubMed e Embase.

As ações em torno da infodemia relacionada à COVID-19 acontecem a partir de diferentes iniciativas internacionais, nacionais, institucionais e pessoais, dentre as quais destaca-se o trabalho da OMS, que vem fazendo esforço para conter as informações falsas usando informação baseada em evidência médica/ clínica, de modo que as pessoas tenham acesso às informações adequadas, conforme relatado pelo diretor geral da organização, Doutor Tedros Adhanom Ghebreyesus, em conferência realizada em 15 de fevereiro de 2020. Para isso, as atividades estão organizadas na Rede de Informação para Epidemias - WHO Information Network for Epidemics (EPIWIN), que tem como objetivo oferecer acesso a recomendações e informações atuais, precisas, fáceis de entender e provenientes de fontes confiáveis, sobre eventos de saúde pública e surtos.

Fighting this infodemic is the new front in the COVID-19 battle (Child, 2020). In the 'post-truth' era, audiences are likely to believe information that appeals to their emotions and personal beliefs, asopposed to information that is regarded as factual and or objective (Maore $t$, 2017). This poses a major global risk and a threat to public health. Thus, it becomes vital to educate people generally, and youth in particular, about the nature of fake News and negative outcomes of sharing such news. The UNESCO is making efforts to counter misinformation and promote the facts about the COVID-19 disease.

A ação biblioteconômica para evitar a desinformação no contexto pandêmico e a infodemia, de acordo com Naeem e Bhatti (2020), tem espaço em ações educacionais, especialmente naquelas de competência em informação, para alertar as pessoas sobre como identificar informações (e notícias falsas).

\section{DESINFORMAÇÃO}

A desinformação não é uma novidade ou uma inovação da contemporaneidade. Darnton (2017) exemplifica que no século VI, no Império Bizantino, Procópio divulgava notícias falsas a fim de manchar a reputação do imperador. No século passado, tem-se que em 1959 a União Soviética estabeleceu dentro do KGB (Komitet Gosudarstvennoi Bezopasnosti - Comitê de Segurança do Estado) uma unidade especial denominada Departamento de Medidas Ativas, especializada em desinformação - no russo, dezinformatsiya (VOLKOFF, 2004). Movimentos como a antivacinação ou as teorias de terra plana surgem embasados em desinformação, com vistas a deslegitimar 0 conhecimento científico (POSETTI; BONTCHEVA, 2020).

Tal como conhecemos hoje, a noção de desinformação vem do inglês disinformation no período de Guerra Fria e foi apresentada no Chambers Twentieth Century 
Dictionary, Londres, em 1972, com a seguinte definição "vazamento proposital de informações enganosas" (VOLKOFF, 2004).

As pesquisas e os estudos sobre desinformação trazem à tona diversas definições e evidenciam, por vezes, questões políticas. Em geral, os autores e as autoras que trabalham com o tema remetem às informações enganosas e muitos as diferenciam por tipos. Desse modo, faz-se a diferenciação de três tipos de informações falsas, imprecisas ou enganosas (VOLKOFF, 2004; FALLIS, 2015; WARDLE; DERAKHSHAN, 2017):

a) misinformation: informação falsa, imprecisa ou enganosa sem intenção de prejudicar;

b) disinformation: informação falsa, imprecisa ou enganosa para causar algum prejuízo;

c) mal-information: informação falsa, imprecisa ou enganosa para causar algum prejuízo à algum grupo específico, motivada por ódio.

Cabe ressaltar que a informação, assim como a desinformação, aqui apresentada, observa o locus discursivo. Desse modo, tem-se a compreensão da informação como construção social e a partir da participação de diferentes sujeitos na produção e uso do conhecimento (HJØRLAND; ALBRECHTSEN, 1995; MORAES; CAMPOS, 2016; SAVOLAINEN, 2007). Uma informação pode ser verdadeira ou falsa a depender da intenção de sua produção e/ou uso em determinado contexto. Assim sendo, o dano, ou a intenção de causar prejuízo, pode ser feito pela forma que um conteúdo é usado. Por exemplo, quando os dados que indicam que a população negra tem a maior taxa de mortalidade em decorrência da COVID-19 (SANTOS et al., 2020) são usados sem que sejam consideradas as especificidades dos contextos e, neste caso, as assimetrias e desigualdades estruturais, para fundamentar algum tipo de racismo e/ou discriminação, "coronaracismo"5 (JING ZENG, 2020), tem-se uma mal-information.

De acordo com Fallis (2015), essa é uma prática que pode ser extremamente perigosa e que deve ser observada a partir de três características básicas:

a) desinformação é informação;

b) desinformação é uma informação enganosa;

c) desinformação não é uma informação acidentalmente enganosa.

A desinformação tende a ser mais restrita no contexto das informações científicas, pois o método, como característica da ciência, exige a reprodução das experiências para verificação de resultados similares (FALLIS, 2015). Assim, as informações do cotidiano são mais vulneráveis às "contaminações", uma vez que não pressupõem rigor metodológico em sua produção e uso. De modo a exemplificar os tipos de desinformação, Wardle e Derakhshan (2017) apresentam:

a) conteúdo enganoso (misleading content)

b) sátira ou paródia (satire or parody);

c) conteúdo fabricado (fabricated content);

d) conteúdo impostor (imposter content)

e) conteúdo manipulado (manipulated content);

f) contexto falso (false context);

g) conexão falsa (false connection).

50 "coronaracism" é um termo usado para identificar casos de racismo e discriminação em que minorias são culpadas pela pandemia da COVID-19. 
Os autores destacam a necessidade de um maior detalhamento dos tipos de desinformação, de modo a abarcar a complexidade do tema. No contexto pandêmico da COVID-19, tem-se a emergência da desinfodemia como uma variação da desinformação na infodemia.

\section{DESINFORMAÇÃO E INFODEMIA: DESINFODEMIA}

No escopo da desinformação e da infodemia, tem-se a desinfodemia, que surge em 2020, no contexto pandêmico da COVID-19, de acordo com a Organização das Nações Unidas para a Educação, a Ciência e a Cultura (UNESCO).

A desinfodemia apresenta-se como um recorte da infodemia, na medida em que os problemas das dinâmicas informacionais deixam de estar relacionados ao volume de informação e passam a ser as informações falsas e não confiáveis relacionadas à pandemia, de maneira premeditada ou não (POSETTI; BONTCHEVA, 2020).

Posetti e Bontcheva (2020) destacam que o acesso à internet/ web tem pontos positivos, como o acesso à informação de qualidade sobre saúde pública aos cidadãos. Contudo, alertam também que as desinformações são mais disseminadas e, por isso, mais difíceis de controlar e que podem, entre outras coisas, ser exploradas para fins racistas, xenofóbicos, sexistas e de posicionamento político. Em meio à pandemia, isso pode significar um número maior de mortes. Além de polarizar as pessoas a partir do ódio.

A desinfodemia surge como uma desinformação em meio à pandemia ao expor as pessoas aos riscos das informações falsas, a partir da deslegitimação da produção do conhecimento científico e exposição pública, com (disinformation) ou sem intencionalidade (misinformation), mas que o objetivo pode ser desde uma "brincadeira" até as disputas políticas ou as vantagens comerciais de um determinado grupo farmacêutico, por exemplo.

Posetti e Bontcheva (2020) elencaram quarto formatos-chave de desinformação na pandemia da COVID-19, desinfodemia, a saber:

a) narrações e memes emocionais - combinam a emoção e a opinião com mentiras ou imprecisões. São bastante usados em aplicativos de mensagens pessoais;

b) sites e identidades inventados - usados para publicações que parecem razoaveis, mas que contêm dados e informações falsas;

c) imagens e vídeos alterados, inventados ou descontextualizados para confundir e promover desconfiança e/ou emoções e/ou polarizações.

d) ações de desinformação para promover desconfiança e/ou emoções e/ou polarizações e acessar ilicitamente dados pessoais de saúde. Pode utilizar phishing, spam, bots e trolls.

Tais formas e formatos utilizam-se de opiniões, crenças, sentimentos, polarizações, para que possam alcançar as pessoas de modo simplificado ao ignorar a complexidade das questões sociais e informacionais em formas de textos, imagens, vídeos e áudios (POSETTI; BONTCHEVA, 2020). De acordo com as autoras, os temas são, em geral, relacionados aos seguintes conteúdos na esfera da COVID-19:

a) origem e propagação do vírus;

b) estatísticas falsas e enganosas;

c) impactos econômicos (e sanitários) da pandemia; 
d) descrédito dos jornalistas e dos meios de comunicação;

e) ciência média: sintomas, diagnóstico e tratamento;

f) impactos na sociedade e no meio ambiente;

g) politização com ponto de vista;

h) promovidos para lucro fraudulento a partir dos dados pessoais;

i) sobre celebridades que supostamente foram contaminadas.

O contexto pandêmico, que já carrega tantas questões negativas na sociedade, somado às informações falsas, enganosas e imprecisas, podem causar prejuízo à saúde física, mental e emocional dos indivíduos e de toda a sociedade, especialmente no âmbito da saúde pública. Por isso, há que se tratá-los sob a perspectiva da educação que, para a UNESCO, surge como uma das formas de tratamento dessa patologia e dialoga com os direitos humanos e com os Objetivos de Desenvolvimento Sustentável da Agenda 2030, no sentido de possibilitar que as pessoas tenham acesso à informação, para o exercício da cidadania, com saúde e qualidade de vida.

\section{EDUCAÇÃO EM INFORMAÇÃO E COMPETÊNCIA EM INFORMAÇÃO}

A educação em informação vem assumindo diferentes métodos e formas ao longo dos anos, dentre os quais estão, por exemplo, a competência em informação (Information Literacy) ou a competência em mídia e em informação (Media and Information Literacy), que é apontada por instituições como a Unesco e a Comissão Europeia, como possibilidade para evitar ou combater a desinformação (EUROPEAN COMMISSION, 2018; UNESCO, 2020).

A relação entre educação em informação, a desinformação e a desinfodemia exige que seja considerado que não existe meia verdade ou meia informação. A desinformação é uma informação, mas ela é uma informação falsa, sobretudo (LEVITIN, 2019). Também há que considerar que um mesmo conteúdo pode ser uma informação ou uma desinformação, a depender do contexto e da comunidade. Levitin (2019) entende que algumas opiniões podem ser verdadeiras, mas as informações não devem ser falsas, conforme ilustração 1 abaixo.

\section{Ilustração 1 - Opinião, fato e mentira}
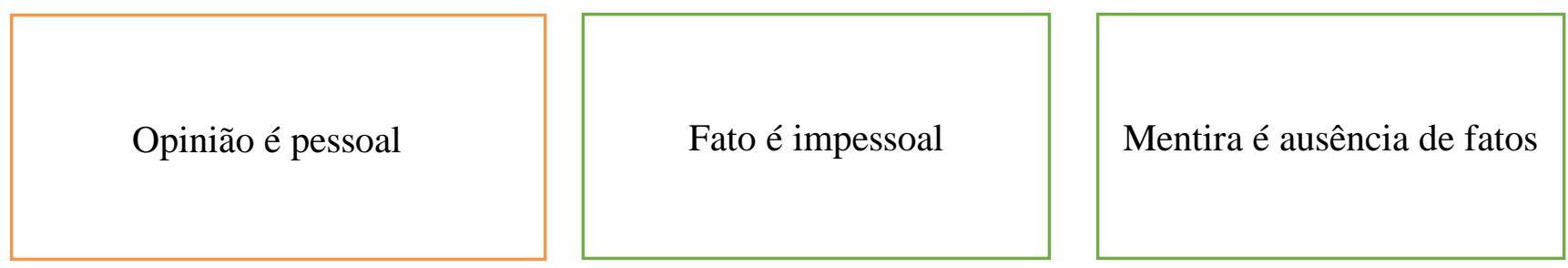

Fonte: Adaptado de Levitin (2019).

Dito de outro modo, significa que se algo é mentiroso, é porque não tem qualquer fato relacionado e trata-se, portanto, somente de uma opinião. Por isso o pensamento crítico é vital, especialmente neste contexto em que a saúde pública é ameaçada, pois ele nos ajuda a refletir e avaliar fatos para que cheguemos às conclusões com base em evidência. E é neste espaço que a educação em informação se destaca, na medida em que a criticidade é desenvolvida a partir de práticas informacionais de construção do conhecimento. 
A educação em informação, enunciada nesta seção, tem ligação com a Information Literacy, em nível internacional e com a Competência em Informação, em nível nacional. No Brasil, o termo ainda é objeto de disputas por sua comunidade discursiva. Sem que pese os pontos de vista específicos, a escolha por essa tradução está relacionada à Declaração de Maceió, elaborada em 2010, por um grupo de bibliotecários e pesquisadores da área, que conclamam a comunidade para, entre outras coisas, o exercício da cidadania e o aprendizado ao longo da vida, a partir da educação.

A Competência em Informação (Colnfo) é compreendida aqui como uma prática sociotécnica que permite reconhecer quando a informação é necessária e, a partir disso, saber localizar, avaliar e utilizar a informação de forma eficaz, crítica e ética. Trata-se, portanto, de uma ação complexa e contínua no universo informacional, que considera a tecnologia, para o aprendizado ao longo da vida a partir de experiências solidárias, coletivas, colaborativas e comunitárias em domínios do conhecimento (AMERICAN LIBRARY ASSOCIATION, 2000; 2010; 2016; TUOMINEN; SAVOLAINEN; TAJLA, 2005). De outro modo, significa dizer que abrange as experiências solidárias e coletivas vivenciadas nas dinâmicas de aprendizagem que acontecem em diferentes contextos e temáticas no curso das atividades da vida. Para isso, enfatiza a importância do acesso à informação, da avaliação e do uso de forma responsável e crítica, sob uma perspectiva que incorpora todos os tipos de formatos, suportes e conteúdos informacionais, nas dimensões da vida pessoal, profissional, educacional e social. Dessa forma, o pensamento crítico estimulado pela competência em informação não significa desacreditar em tudo, pelo contrário, significa que devemos distinguir entre opinião e fato (evidência).

Agosto (2018) afirma que a ascensão das fake news6 (que aqui amplia-se e considerase a desinformação) está relacionada ao aumento da dependência das fontes de informação e de notícias online, que são produzidas também pelos usuários e não exclusivamente por redatores, pesquisadores e acadêmicos profissionais.

Um outro dado que influencia nos aspectos da prática informacional, que promove o acesso às informações falsas, é que muitos leitores preferem as mídias socias aos jornais tradicionais, no acesso às notícias e, mais se interessam fundamentalmente pelas manchetes (na maioria das vezes Clickbait $^{7}$ ). Sob o ponto de vista da produção, tem-se, de acordo com Vosoughi, Roy e Aral (2018), que as informações falsas tendem a ser mais compartilhadas por pessoas (e não por robôs) e, podem, portanto, dar mais visibilidade a quem as produz ou dissemina.

Considerar o compartilhamento e as mídias sociais digitais pode indicar que o formato online é o problema central das informações falsas. No entanto, a centralidade das discussões deve considerar como as informações são criadas, avaliadas (validadas) e distribuídas, seja nos formatos tradicionais, seja nos formatos online. A grande questão é considerar a necessidade de avaliação daquilo que é verdadeiro ou falso informacionalmente, independentemente da forma ou do formato.

Para Agosto (2018), os (as) bibliotecários (as) e outros profissionais da informação são experts em informações e educadores de informação. Essa característica tem ligação com o conhecimento que eles têm sobre como as informações são criadas, distribuídas e usadas em diferentes comunidades no cotidiano. Tais atividades relacionam-se com

\footnotetext{
${ }^{6}$ Fake News, em tradução direta, significa notícias falsas e podem ser vistas como um tipo de desinformação.

7 Estratégia de divulgação online que usa títulos sedutores e/ou sensacionalistas como isca para o acesso.
} 
a noção de competência em informação na medida em que elas podem promover, entre outras coisas, a participação efetiva com cidadania em sociedades democráticas. O olhar crítico e ético só é possível se a leitura do mundo preceder à leitura da palavra, pois a educação é emancipadora no sentido do diálogo e não da formação acadêmica do ensino tradicional (FREIRE, 2011) e (FREIRE, 2015). Desse modo, as ações de competência em informação feitas por bibliotecários (as) não devem ter o foco na informação ou nas notícias em processos de validação ou checagem, visto que a educação deve voltar-se para as pessoas.

\section{DESINFODEMIA E AÇÕES DE COMPETÊNCIA EM INFORMAÇÃO}

Diferentes instituições desenvolveram ações de competência em informação neste contexto pandêmico da COVID-19. Em todo o mundo pode-se observar que as bibliotecas, que estão com seus acervos fechados, têm desenvolvido e promovido serviços de informação em suas páginas na internet sobre temas relacionados à informação, que passam por cursos sobre acesso às bases de dados até entrevistas com especialistas, em diferentes ramos do conhecimento. Muitas dessas iniciativas podem ser categorizadas como ações de educação em informação e/ ou de competência em informação.

Sob o ponto de vista da desinfodemia, a Unesco declara que a competência [em mídia e] em informação é um dos direitos dos cidadãos. A competência em informação é apresentada no escopo das ações voltadas para o público-alvo das informações falsas sobre a COVID-19, com o objetivo de promover o pensamento crítico e a avaliação de fontes de informação em diferentes ambientes e dinâmicas informacionais (POSETTI; BONTCHEVA, 2020).

Os projetos de competência em informação na desinfodemia vêm sendo amplamente desenvolvidos e é possível identificá-los em instituições do campo da informação, bibliotecas e unidades de informação, que atuam nessa frente. Em face do distanciamento social para conter a pandemia, foram realizados em ambientes digitais. Exemplo disso são os treinamentos em bases de dados ou conversas com especialistas em determinadas áreas ou objetos informacionais que foram promovidos por sistemas de bibliotecas universitárias da Universidade Federal do Rio de Janeiro (UFRJ), da Universidade Federal do Estado do Rio de Janeiro (UNIRIO) e da Universidade Federal Fluminense (UFF).

Como estratégia metodológica, serão indicadas neste texto duas ações realizadas. A primeira em nível internacional e a segunda em nível nacional. São iniciativas de competência em informação que foram organizadas em formato textual e multimídia, respectivamente. A diferença de formatos, no entanto, não exclui a participação das pessoas na medida em que nas duas possibilidades devem ser consideradas as especificidades das dinâmicas informacionais (contextos, pessoas, objetivo etc.).

No âmbito internacional, tem-se a International Federation of Library Associations and Institutions (IFLA), que já vinha promovendo atividades para evitar a propagação de desinformação, e que publicou um infográfico neste ano sobre como identificar notícias falsas na esfera da COVID-19, conforme ilustração 2 abaixo. 


\section{Ilustração 2 - Como identificar notícias falsas - edição COVID-19}

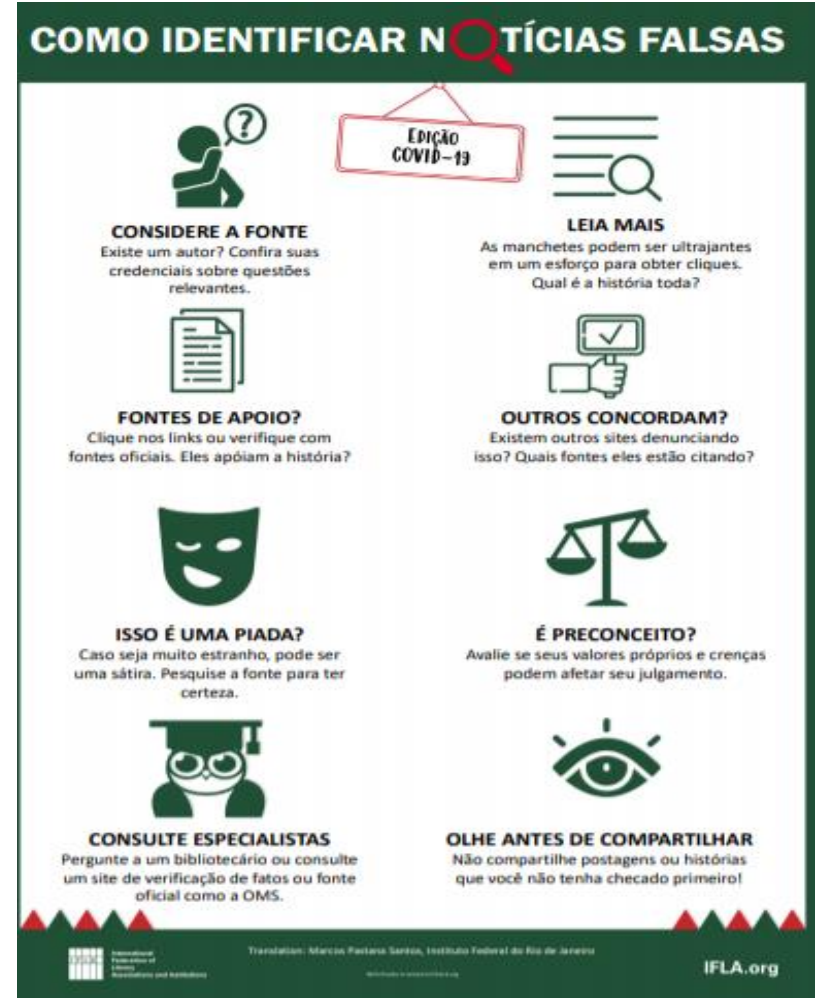

Fonte: International Federation of Library Associations and Institutions (2020).

Trata-se de uma iniciativa que tem como objetivo evitar desinformação na pandemia, a partir da indicação de elementos-chave, que podem auxiliar na verificação/ checagem/ avaliação de notícias e de outras fontes de informação a partir de oito ações. Destaca-se a instituição fez outro infográfico em 2017 e diferenciou deste ao retirar a indicação para verificação do (a) autor (a) e da data, além de inserir a indicação sobre a necessidade de verificação de outras fontes e a importância do olhar crítico e ético para a informação/ notícia. Trata-se, portanto, de uma proposta que quer ser menos objetiva e mais participativa no processo de verificação/ checagem/ avaliação de notícias e de outras fontes de informação.

A iniciativa no Brasil, foi o VI Fórum sobre Competência em Informação: pesquisas e práticas, realizado no Rio de Janeiro, nos dias 23, 24 e 25 de junho de 2020, online, via canal da Rede de Competência em Informação, Formada por bibliotecários (as) e pesquisadores (as) independentes e vinculados às seguintes instituições de ensino e pesquisa: Universidade Federal do Rio de Janeiro, Universidade Federal do Estado do Rio de Janeiro, Fundação Oswaldo Cruz, Rede Baixada Literária, Instituto Brasileiro de Informação em Ciência e Tecnologia, Companhia de Pesquisa de Recursos Minerais e Colégio Pedro Il., que teve como objetivo promover um debate sobre as abordagens teóricas, práticas e de pesquisas em infodemia e desinformação na pandemia da COVID-19. Para isso, participaram bibliotecários e bibliotecárias que desenvolveram atividades para o atendimento em meio à pandemia em bibliotecas universitárias e institutos de pesquisas; além de pesquisadoras e pesquisadores que atuam com o tema da desinformação ou da competência em informação ou da competência em mídia em nível nacional e internacional (REDE DE COMPETÊNCIA EM INFORMAÇÃO DO ESTADO DO RIO DE JANEIRO). 


\section{CONSIDERAÇÕES FINAIS}

Este artigo científico teve como objetivo a apresentação de ações de competência em informação no âmbito da desinfodemia da COVID-19. Para isso, procurou-se elencar atividades que contemplam dois eixos indicados pela Unesco, a saber: a avaliação/ checagem de fontes de informação e a educação em dinâmicas informacionais.

Sob o ponto de vista teórico tem-se que a competência em informação, no contexto de desinformação e desinfodemia, assume um destaque nos temas a serem desenvolvidos no campo de estudos da informação, na medida em que lhe interessa a educação em dinâmicas informacionais, em diferentes comunidades e contextos. Ressalta-se a leitura do mundo de Paulo Freire como uma epistemologia que direciona a educação sob o ponto de vista do diálogo e, portanto, da interação na construção do conhecimento. Desse modo, a noção de competência em informação não deve ser diretamente relacionada às estruturas formais da educação e, principalmente, do ensino ao ter como foco a práxis do dia-a-dia de modo que todas as pessoas participam da construção da informação e do conhecimento.

Cabe ressaltar que os estudos e prática na desinfodemia são recentes e crescem no contexto da COVID-19, no ano de 2020. Acredita-se que os contextos pandêmicos e pós-pandêmicos exigem outras discussões sobre desinformação, que devem compor a agenda das discussões sociais. Desse modo, como possibilidade de pesquisas futuras, tem-se a educação em informação e as ações de competência [em mídia e] em informação, como um direcionador de temas e assuntos que podem promover a cidadania.

\section{REFERÊNCIAS}

AGOSTO, Denise. Information literacy and libraries in the age of fake news. Exeter: Libraries Unlimited, 2018.

AMERICAN LIBRARY ASSOCIATION. Framework for information literacy for higher education. Chicago: The Association of College and Research Libraries, 2016.

AMERICAN LIBRARY ASSOCIATION. Information literacy competency standards for higher education. Chicago: The Association of College and Research Libraries, 2000.

AMERICAN LIBRARY ASSOCIATION. Association of College and Research Libraries. Information literacy competency standards for higher education. Chicago, 2010.

BECHARA, Evanildo. Infodemia. Rio de Janeiro: Academia Brasileira de Letras., 2020. Disponível em: https://www.academia.org.br/artigos/infodemia. Acesso em: 9 ago. 2020.

DARNTON, Robert. A verdadeira história das notícias falsas. El País Brasil, Madrid, 1 maio 2017.

DECLARAÇÃO de Maceió sobre a competência em informação. In: CONGRESSO BRASILEIRO DE BIBLIOTECONOMIA E DOCUMENTAÇÃO, 24., 2010, Maceió. Anais... 2010.

EUROPEAN COMMISSION. A multi-dimensional approach to disinformation: report of the independent High level Group on fake news and online disinformation. Bruxelas: Directorate-General for Communications Networks, Content and Technology, 2018. 
FALLIS, Don. What is disinformation?. Library Trends, v. 63, n. 3, p. 401-426, 2015.

FREIRE, Ana Maria Araújo. A leitura do mundo e a leitura da palavra em Paulo Freire. Cadernos CEDES, v. 35, n. 96, p. 291-298, 2015.

FREIRE, Paulo. A importância do ato de ler: em três artigos que se completam. 51. ed. São Paulo: Cortez, 2011.

HJØRLAND, B.; ALBRECHTSEN, H. Toward a new horizon in information science: domain-analysis. Journal of the American Society for Information Science, New York, v. 46, n. 6, p. 400-425, Jul. 1995.

INTERNATIONAL FEDERATION OF LIBRARY ASSOCIATIONS AND INSTITUTIONS. HOW to spot fake news: COVID-19 edition. Den Haag: IFLA, 2020.

JING ZENG. Sensationalist media is exacerbating racist coronavirus fears: we need to combat it. The Guardian, 28 Feb. 2020. Disponível em:

https://www.theguardian.com/commentisfree/2020/feb/28/sensationalist-media-isexacerbating-racist-coronavirus-fears-we-need-to-combat-it. Acesso: 10 ago. 2020.

LEVITIN, Daniel Joseph. O guia contra mentiras: como pensar criticamente na era da pós-verdade. São Paulo: Objetiva, 2019.

MORAES, R. P. T.; CAMPOS, M. L. A. Mapeamento de domínios do conhecimento: uma proposta metodológica. In: ENCONTRO DA ASSOCIAÇÃO DE EDUCADORES E PESQUISADORES DE BIBLIOTECONOMIA, ARQUIVOLOGIA, CIÊNCIA DA INFORMAÇÃO E DOCUMENTAÇÃO DA IBEROAMÉRICA E CARIBE, 10., 2016, Belo Horizonte. Anais... Belo Horizonte: UFMG, 2016.

NAEEM, Salman Bin; BHATTI, Rubina. The Covid-19 'infodemic': a new front for information professionals. Health Information and Libraries Journal, 2020. Disponível em: https://doi.org/10.1111/hir.12311. Acesso em: 10 ago. 2020.

ORGANIZAÇÃO DA NAÇÕES UNIDAS. Agenda 2030. Traduzido pelo Centro de Informação das Nações Unidas para o Brasil (UNIC Rio). New York: ONU, 13 out. 2015.

ORGANIZAÇÃO PAN-AMERICANA DA SAÚDE. Folha informativa COVID-19 - Escritório da OPAS e da OMS no Brasil. 2020. Disponível em: https://www.paho.org/pt/covid19. Acesso em: 10 ago. 2020.

PRADO, Marcelo Freitas do et al. Análise da subnotificação de COVID-19 no Brasil. Revista Brasileira de Terapia Intensiva, São Paulo, v. 32, n. 2, p. 224-228, jun. 2020. Disponível em: http://www.scielo.br/scielo.php?script=sci_arttext\&pid=S0103507X2020000200224\&lng=en\&nrm=iso. Acesso em: 4 nov. 2020.

POSETTI, Julie; BONTCHEVA, Kalina. Desinfodemia: descifrando la desinformación sobre el COVID-19. Paris: UNESCO, 2020. Disponível em:

https://en.unesco.org/sites/default/files/disinfodemic_deciphering_covid19_disinform ation_es.pdf. Acesso em: 10 ago. 2020.

REDE de Competência em Informação do estado do Rio de Janeiro. In: FÓRUM SOBRE COMPETÊNCIA EM INFORMAÇÃO: pesquisas e práticas no estado do Rio de Janeiro, 6. 2020, Rio de Janeiro. Anais eletrônicos... Rio de Janeiro: [s.n.], jun. 2020. 
Disponível em: https://www.youtube.com/channel/UCfFds8x5HXHpsyccQaSjeCw. Acesso em: 17 jul. 2020.

SANTOS, Boaventura de Sousa. A cruel pedagogia do vírus. Coimbra: Almedina, 2020.

SANTOS, Márcia Pereira Alves dos et al. População negra e Covid-19: reflexões sobre racismo e saúde. Estudos Avançados, São Paulo, v. 34, n. 99, p. 225-244, maio/ago. 2020. Disponível em: https://www.scielo.br/scielo.php?script=sci_arttext\&pid=S010340142020000200225 . Acesso em: 17 jul. 2020.

SAVOLAINEN, R. Information behavior and information practice: reviewing the "umbrella concepts" of information-seeking studies. The Library Quarterly, Chicago, v. 77, n. 2, p. 109-132, Apr. 2007.

TUOMINEN, K.; SAVOLAINEN, R.; TALJA, S. Information literacy as a sociotechnical practice. The Library Quarterly, Chicago, v. 75, n. 3, p. 329-345, 2005.

UNESCO. Stop COVID-19 disinformation at the root with media and information literacy. Paris, 7 maio 2020.

VOLKOFF, Vladimir. Pequena história da desinformação: do cavalo de Tróia à internet. Curitiba: Ed. Vila do Príncipe, 2004.

VOSOUGHI, Soroush; ROY, Deb; ARAL, Sinan. The spread of true and false news online. Science, v. 359, n. 6380, p. 1146-115109, 2020.

WARDLE, Claire; DERAKHSHAN, Hossein. Information disorder: toward an interdisciplinary framework for research and policy making. [S.I.: s.n.], 20--? 